\title{
Identificação humana através da sobreposição de imagens
}

\section{Human identification through image superimposition}

\author{
Luiz Airton Saavedra de Paiva1', Rodolfo Francisco Haltenhoff Melani², \\ Silvia Virginia Tedeschi Oliveira ${ }^{3}$
}

\begin{abstract}
Paiva LAS de, Melani RFH, Oliveira SVT. Identificação humana através da sobreposição de imagens. Saúde, Ética \& Justiça. 2005;10(1/2):1-5.

RESUMO: A identificação humana como atividade pericial pode ser realizada através de diferentes técnicas. Muitas vezes a escassez de registros em vida (ante-mortem) inviabiliza a aplicação de técnicas mais seguras. O presente trabalho relata um caso onde a técnica de superposição de imagens restou como única possibilidade de identificação de um indivíduo. Foram utilizadas fotografias do crânio de um esqueleto submetido a exame antropológico-forense, e fotografias da pessoa desaparecida. A sobreposição das imagens conseguida através do Programa Adobe ${ }^{\circledR}$ Photoshop ${ }^{\circledR}$ cs 6.0 versão para Windows, pela facilidade de execução e baixo custo, revelou-se fundamental, junto a outras evidências, na identificação deste caso.
\end{abstract}

DESCRITORES: Antropologia forense. Medicina legal. Fotografia. Odontologia legal.

\section{INTRODUÇÃO}

A identificação humana é uma atividade pericial que pode ser realizada no âmbito da Antropologia Forense por meio de diferentes técnicas. Entre elas, a reconstrução facial aparece como um importante recurso, já que permite a reprodução de características perdidas ou desconhecidas de um indivíduo, visando seu reconhecimento, ou quando necessário, contribuindo para sua identificação.

Aulsebrook et al. ${ }^{1}$ divide a reconstrução facial em quatro categorias:

1. reposicionamento do tecido mole, danificado ou distorcido, sobre o crânio;
2. uso de transparências e desenhos em sistemas tipo identikit (retrato falado);

3. técnicas de sobreposição gráfica, fotográfica ou através de vídeo;

4. reconstrução plástica ou tridimensional sobre o crânio, com o uso de argila.

No presente trabalho, faremos a descrição de um caso onde foi utilizada a técnica da sobreposição de imagens com a finalidade de identificação de um indivíduo.

A sobreposição de imagens pode ser entendida como um meio auxiliar da identificação, no entanto, em algumas circunstâncias, pode se tornar referência

\footnotetext{
${ }^{1}$ Mestre e Doutor em Ciências pela Faculdade de Medicina - USP.

${ }^{2}$ Mestre e Doutor em Odontologia Legal pela Faculdade de Odontologia - UNICAMP.

${ }^{3}$ Especialista em Odontologia Legal pela Faculdade de Odontologia - USP.

Endereço para correspondência: Luiz Airton Saavedra de Paiva. Av. Cap. Manoel Rudge, 70 - Jdm. Monte Líbano, Mogi das Cruzes, SP. CEP: 08780-290. e-mail: luizairtonsaavedra@terra.com.br
} 
Paiva LAS de, Melani RFH, Oliveira SVT. Identificação humana através da sobreposição de imagens.

significante para o direcionamento de pesquisas forenses, com o propósito de obtenção da identificação do indivíduo. Nos casos onde inexistam outros registros realizados em vida (ante-mortem), como por exemplo: ficha odontológica ou radiografias, a existência de fotografias pode ser muito útil com vistas à realização da técnica de sobreposição de imagens.

De acordo com Glaister e Brash² a superposição de imagens foi usada já no ano de 1867, por Welcker. Desde então, ocorreram grandes avanços na produção de imagens, que permitiram o seu aprimoramento. Inicialmente, estudos foram realizados através da sobreposição fotográfica ${ }^{3}$, evoluindo para o emprego da vídeo-sobreposição ${ }^{4,5,6}$, representando um grande avanço na capacidade de manipulação de imagens. Atualmente, com o desenvolvimento da informática, pode-se contar com os recursos da computação gráfica ${ }^{7}$. Nesta técnica, digitalizam-se as imagens do crânio sem identificação e da fotografia da pessoa a quem se atribui essa identidade, para posterior verificação de coincidências anatômicas entre as imagens sobrepostas (antroposcopia), assim como, confrontação de medidas entre pontos de reparo do crânio e da face (antropometria).

A sobreposição de imagens com o auxílio da computação gráfica, no caso aqui descrito, foi realizada através da utilização do software Adobe ${ }^{\circledR}$ Photoshop ${ }^{\circledR}$ CS 6.0 ( ) (1990-2003 Adobe Systems Incorporated), em sua versão para o sistema Windows.

\section{APRESENTAÇÃO DE CASO}

No final de 2003, procurou o Instituto Médico Legal (IML) de Guarulhos (SP) uma mulher que alegava ter recebido, apenas recentemente, informações de que seu marido, desaparecido em 26 de dezembro de 1995, poderia ter sido autopsiado como desconhecido neste Instituto.

Foi-lhe então apresentado o arquivo de fotos de cadáveres desconhecidos, com registro de entrada no IML em data posterior ao desaparecimento de seu marido, assim como foram apresentadas cópias de laudos de exames antropológico-forenses, referentes ao mesmo período.

Alguns dados antropológico-forenses, obtidos através de perícia realizada em um cadáver recebido no estado de completa esqueletização, eram coincidentes com os dados biotipológicos de seu marido. Com isso, a mulher foi orientada a procurar, junto à família, registros de seu marido feitos em vida (ante-mortem), que pudessem, através da minuciosa confrontação com elementos obtidos pelo exame antropológico-forense (post-mortem), possibilitar sua identificação, tais como: fichas dentárias, aparelhos ou próteses que utilizasse, radiografias realizadas, fotos; assim como descrição de roupas e pertences que usava quando do seu desaparecimento.

Após infrutífera tentativa de obter registro dentário ou radiografias, que permitiriam conclusões mais precisas, foi encaminhado por ela, um conjunto de pertences do seu marido, constando de: uma carteira profissional, uma abreugrafia e duas fotos coloridas, uma medindo cerca de $13,0 \mathrm{~cm} \times 9,0 \mathrm{~cm}$, tirada cerca de quinze anos antes (Figura 1) e outra, medindo cerca de $15,0 \mathrm{~cm} \times 10,0 \mathrm{~cm}$, feita em 25 de dezembro de 1995, dia de Natal, véspera de seu desaparecimento (Figura 2).

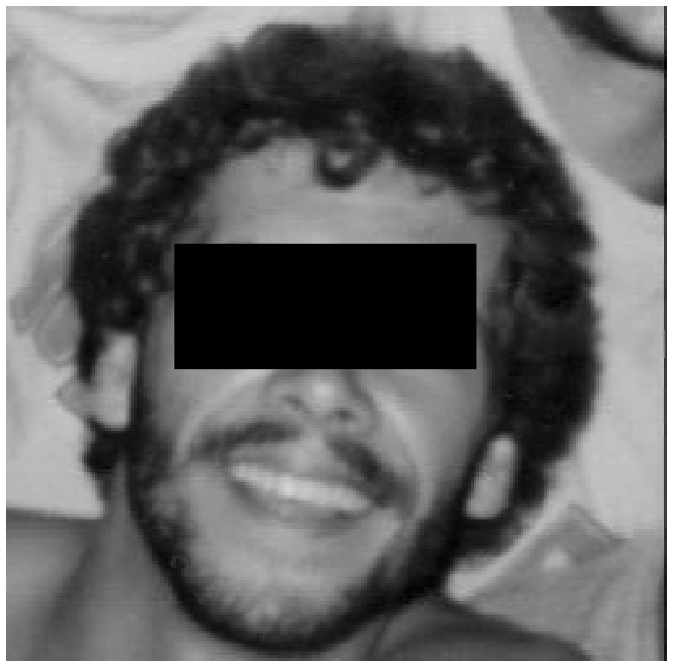

Figura 1 - Imagem facial de frente da pessoa desaparecida, obtida por ampliação de fotografia fornecida por sua esposa.

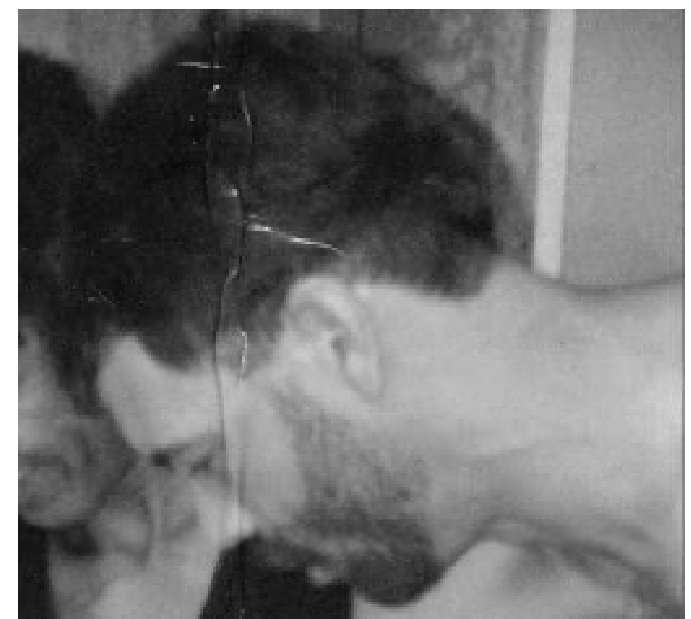

Figura 2 - Imagem facial do perfil lateral esquerdo da pessoa desaparecida, obtida por ampliação de fotografia fornecida por sua esposa. 
Restou como única possibilidade para realizar esta identificação, a técnica de sobreposição fotográfica crânio-facial. Para tanto, encaminhamos ao cemitério, onde foram inumados os despojos do cadáver periciado sob o no 1800/96, pedido de informação a seu respeito, para que fosse solicitada, via judicial, sua exumação para fins de perícia de identificação médico-legal.

Porém, como resposta foi recebida à informação de que estes despojos, por força de interesse administrativo, já haviam sido exumados e encaminhados para o ossário geral do cemitério; de onde sua recuperação fica impossibilitada, devido à ausência de um sistema de registro e identificação dos esqueletos lá depositados. Dessa maneira, a única possibilidade de realizar a técnica proposta seria através das fotografias do crânio, presentes no referido laudo necroscópico.

\section{DESCRIÇÃO DAS TÉCNICAS EMPREGADAS}

Primeiramente, foi realizada a ampliação das fotos recebidas da família, com a finalidade de se obter imagens faciais nas incidências de frente e de perfil esquerdo, e sua posterior digitalização. Em seguida, foram escolhidas, entre as fotos do crânio presentes no citado laudo necroscópico, as mais adequadas para ampliação e posterior digitalização (Figuras 3 e 4).

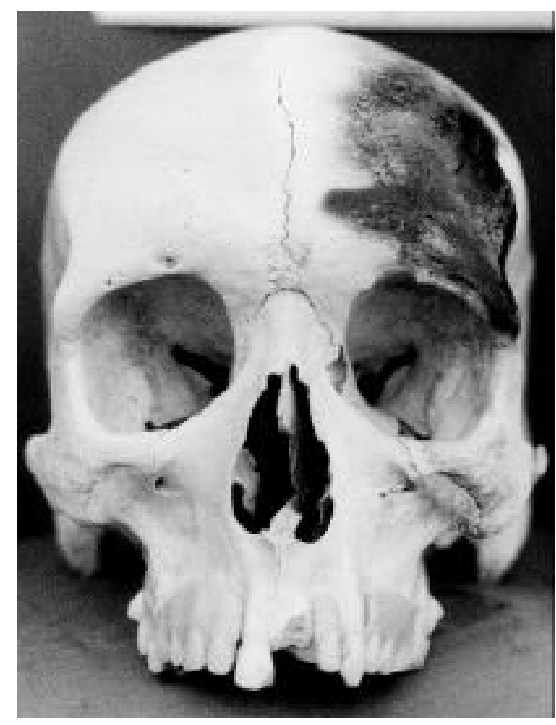

Figura 3 - Imagem do crânio de frente, obtida do Laudo de Exame Antropológico-Forense № 1800/06, do IML de Guarulhos-SP.

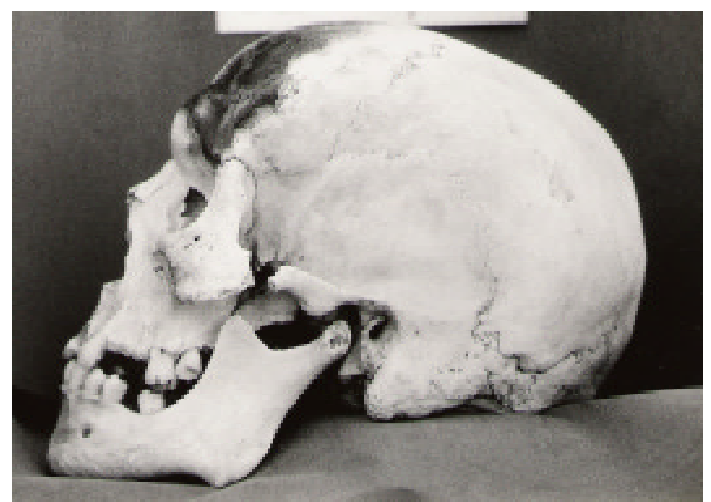

Figura 4 - Imagem do crânio, em perfil lateral esquerdo, obtido do Laudo de Exame Antropológico-Forense № 1800/06, do IML de Guarulhos-SP.

Por meio do programa Adobe ${ }^{\circledR}$ Photoshop ${ }^{\circledR}$ cs 6.0, em sua versão para Windows, foram realizadas rotações axiais das imagens digitalizadas do crânio, de frente e perfil esquerdo, até se obterem incidências idênticas às das fotos cedidas ampliadas, utilizando-se reparos anatômicos para a equalização da escala fotométrica.

Superpostas as imagens craniofaciais, nas incidências de frente e de perfil, respeitada a escala fotométrica para estudo comparativo, foram observadas múltiplas coincidências entre pontos de reparo anatômico do crânio e os correspondentes pontos de reparo faciais, inexistindo qualquer discrepância anatômica que excluísse a identidade entre ambos (Figuras 5 e 6).

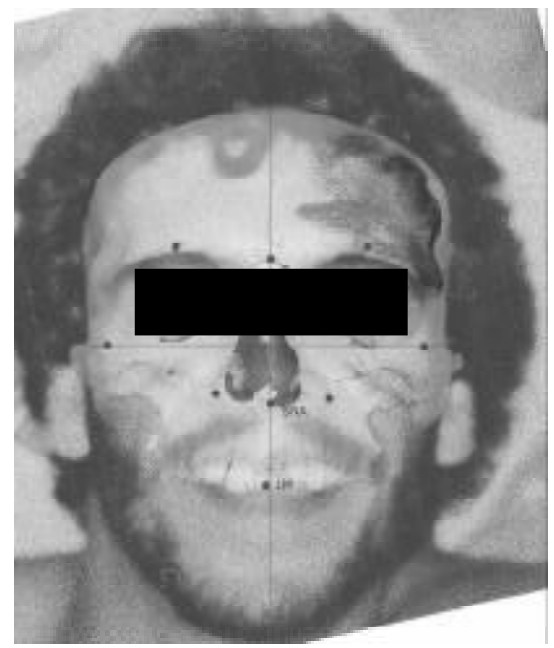

Figura 5 - Sobreposição das imagens do crânio e da face, na incidência de frente. 


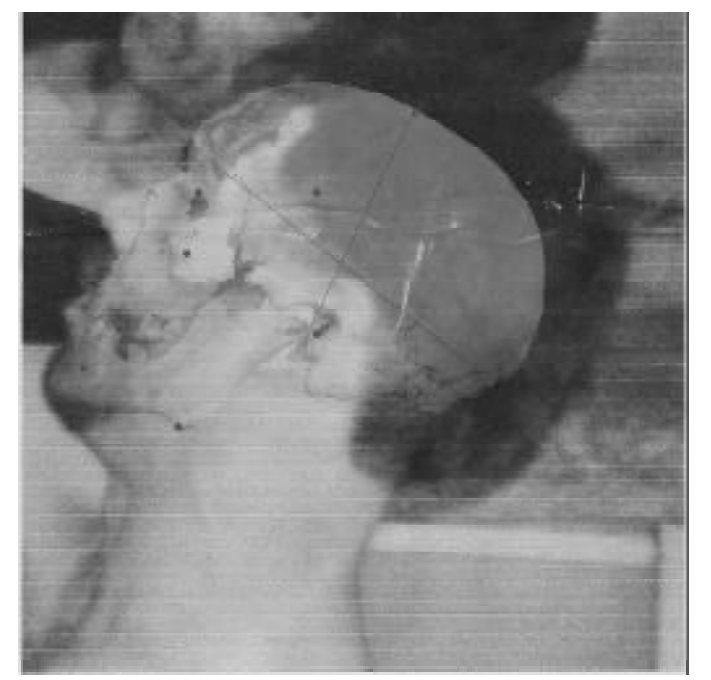

Figura 6 - Sobreposição das imagens do crânio e da face, na incidência de perfil lateral esquerdo.

\section{DISCUSSÃo}

A utilização da técnica de sobreposição de imagens mostra-se de grande importância como auxiliar na identificação humana. Fatores como a presença de dentes no crânio e acesso a fotografias, onde aparecem os dentes do indivíduo, facilitam a comparação, além de proporcionar resultados muitos mais acurados.

Deacoudb com a chsssificaçãodeMckerna! no caso destes fatores estarem presentes, pode-se chegar a uma identificação categórica, ou inequívoca. No entanto, se não há como comparar os elementos dentários através das fotografias, a identificação fica prejudicada, e pode apenas ser classificada como altamente provável, ou apenas consistente.

$\mathrm{Na}$ literatura podemos encontrar diversos relatos onde a sobreposição de imagens foi fundamental na identificação de indivíduos. Mesmo em casos onde a identificação foi classificada como apenas consistente ${ }^{9,10}$, quando somada a outras evidências, pôde-se chegar à conclusão satisfatória ${ }^{11}$. Outro caso, aliando as técnicas de reconstrução ortodôntica ${ }^{12}$ à presença de elementos dentários na fotografia, possibilitou a identificação positiva de uma jovem vítima de assassinato Casos de grande repercussão, como da família Romanov, também puderam ser esclarecidos através da sobreposição de imagens ${ }^{13}$, onde foram obtidas fortes evidências que a filha do Czar, Anastácia, fora de fato assassinada juntamente com a sua família, em 1918.

No caso aqui relatado, a consistência da identificação se fundamenta nos seguintes aspectos:

1. na concordância entre a data do desaparecimento do indivíduo (26/12/1995), anterior ao recebimento do cadáver (01/07/1996), objeto da perícia relatada;

2. nas múltiplas coincidências entre as conclusões do exame antropológico-forense, como: cor da pele, sexo, idade, estatura e época da morte, com dados biotipológicos da pessoa desaparecida, conforme as alegações de sua esposa, somadas à inexistência de algum dado excludente entre as conclusões deste exame antropológico e os dados próprios da pessoa desaparecida;

3. na escassez de registros em vida (antemortem), que pudessem servir como fonte mais confiável, do ponto de vista científico, para confrontação como identidade atribuível, com os dados obtidos pelo exame antropológico-forense (post-mortem);

4. nas múltiplas coincidências entre os pontos craniométricos assinalados na sobreposição das imagens e os correspondentes pontos faciais, tanto na incidência de frente como na de perfil esquerdo (Figuras 5 e 6 );

5. na completa ausência de incoincidência entre os pontos de reparo anatômico crânio-faciais, que se revelariam excludentes da identificação.

Dessa forma, considerando esse conjunto de aspectos, foi possível afirmar com suficiente certeza científica, que o cadáver objeto do exame antropológico-forense, periciado sob o № 1800/96, trata-se da pessoa presente nas fotos encaminhadas para o estudo.

\section{CONCLUSÃO}

O desenvolvimento da tecnologia em todas as áreas da ciência no último século, conduziu a um grande progresso da investigação científica. As técnicas de identificação humana acompanharam esses progressos nas ciências biomédicas. Como exemplo, a validade dos testes de identificação realizados por meio de $D_{N A}{ }^{14}$, já não são mais discutidos. Porém, tecnologias mais sofisticadas para serem utilizadas em identificação médico-legal, necessitam de requisitos mínimos na coleta do material para exame e sua correta conservação, além 
de elevado custo, o que inviabiliza sua aplicabilidade na maioria dos serviços médico-legais em nosso país.

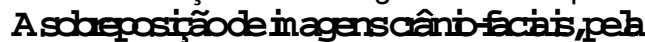
facilibde de exicação e baixo asto do métodb, reveburse um inpoitante auxiliarnas perícias de ìntificaçãohumana.

No caso aqui apresentado, diante da impossibilidade da utilização de autas técricas consideradasmaisseguras, asobueposiçãolealizada, a partir das imagens fornecidas pela família, com as fotografias do crânio presentes no Laudo Necroscópico, revelou-se um método de significativa expressão, por ser a única possibilidade de realização da pretendida identificação.

A técnica de sobreposição de imagens empregada, somada aos outros aspectos descritos, permitiu, neste caso, uma identificação com razoável grau de certeza científica.

Paiva LAS de, Melani RFH, Oliveira SVT. Human identification through image superimposition. Saúde, Ética \& Justiça. 2005;10(1/2):1-5.

ABSTRACT: The human identification as a forensic activity can be done by different techniques. Many times the lack of documentation in life (ante-mortem) make the use of safer techniques not viable. This work describes a case where the image superimposition technique was the only resource left to identify a person. It was used pictures from the skull of a skeleton that had an anthropological forensic examination, and pictures of the missing person. The superimposition ofllemagesdonewith the Addbe Photoshop ${ }^{\oplus}$ cs 6.0 version for Windows software, for its easiness of execution and low cost, reveal itself being fundamental, added to other evidence, in the identification of the case.

KEY WORDS: Forensic anthropology. Forensic medicine. Photography. Forensic dentistry.

\section{REFERÊNCIAS}

1. Aulsebrook WA, Íscan MY, Slabbert JH, Becker $P$. Superimposition and reconstruction in forensic facial identification: a survey. Forensic Sci Int. 1995;75:10120.

2. Glaister J, Brash JC. Medico-legal aspects of the Ruxton case. Edinburgh: Livingstone; 1937. p.14470.

3. Caldwell PC. New questions (and some answers) on the facial reproduction techniques. In: Reichs KJ, et al. Forensic osteology: advances in the identification of human remains. Springfield, IL: Charles C. Thomas; 1986.

4. Iten PX. Identification of skulls by video superimposition. J Forensic Sci. 1987;32:173-88.

5. Koelmeyer TD. Videocamera superimposition and facial reconstruction as an aid to identification. $\mathrm{Am} \mathrm{J}$ Forensic Med Pathol. 1982;3:45-8.

6. Chandra Sekaran P. Positioning skull for video superimposition. Indian Forensic Sci. 1988;2:166-72.

7. Pescel Delfino V, Colona M, Vacca E, Potente F, Introna F Jr. Computer-aided skull face superimposition. Am J Forensic Med Pathol. 1986;7:201-12.

8. Mckenna JJ, Jablonski NG, Fearnhead RW. A method of matching skulls with photographic portraits using landmarks and measurements of the dentition. $J$ Forensic Sci. 1984;29:787-97.

9. Thomas CJ, Nortjé CJ, Van leperen L. A case of skull identification by means of photographic superimposition. J Forensic Odontostomatol. 1986;2:61-6.

10. Solla HE, Iscan MY. Skeletal remains of Dr. Eugenio Antonio Berríos Sagredo. Forensic Sci Int. 1986;116:201-11.

11. Paiva LAS. Identificação médico-legal. Rev Univ Guarulhos - Série Ciên Humanas Sociais, 1997;2(2):41-50.

12. Whittaker DK, Richards BH, Jones ML. Orthodontic reconstruction in victim of murder. $\mathrm{Br} \mathrm{J}$ Orthod. 1998;25:11-4.

13. Kolesnikov LL, Pashinyan GA, Abramov SS. Anotomical appraisal of the skulls and teeth associated with the family of Tsar Nicolay Romanov. Anat Rec. 2001;265:15-32.

14. Jobim LF. DNA \& crime. In: Figini ARL, Silva JRL, Jobim LF, Silva M. Identificação humana. 2a. ed. Campinas: Millennium; 2003. p.280-4. 